\title{
Benthic ecology from space: optics and net primary production in seagrass and benthic algae across the Great Bahama Bank
}

\author{
Heidi M. Dierssen ${ }^{1, *}$, Richard C. Zimmerman ${ }^{2}$, Lisa A. Drake ${ }^{2,3}$, David Burdige ${ }^{2}$ \\ ${ }^{1}$ Department of Marine Sciences/Geography, University of Connecticut, Groton, Connecticut 06340, USA \\ ${ }^{2}$ Department of Ocean, Earth and Atmospheric Sciences, Old Dominion University, 4600 Elkhorn Avenue, Norfolk, \\ Virginia 23529, USA
}

${ }^{3}$ Present address: Science Applications International Corporation, c/o Naval Research Laboratory, Key West, Florida 33041, USA

\begin{abstract}
Development of repeatable and quantitative tools are necessary for determining the abundance and distribution of different types of benthic habitats, detecting changes to these ecosystems, and determining their role in the global carbon cycle. Here we used ocean color remote sensing techniques to map different major groups of primary producers and estimate net primary productivity (NPP) across Great Bahama Bank (GBB). Field investigations on the northern portion of the GBB in 2004 revealed 3 dominant types of benthic primary producers: seagrass, benthic macroalgae, and microalgae attached to sediment. Laboratory measurements of NPP ranged from barely net autotrophic for grapestone sediment with thin microalgal biofilm to highly productive for dense accumulations of brown macroalgae. A logarithmic relationship between NPP and green seafloor reflectance described the general trend in NPP across various benthic constituents. Using a radiative transferbased approach, satellite-derived estimates of NPP for the region totaled $\sim 2 \times 10^{13} \mathrm{~g} \mathrm{C} \mathrm{yr}^{-1}$ across the GBB. The prevailing benthic habitat was mapped as sediment with little to no microalgal biofilm. Moderate to dense seagrass meadows of Thalassia testudinum were the dominant primary producers and contributed over $80 \%$ of NPP in the region. If the vast majority of seagrass leaves decompose in the primarily carbonate sediments, carbonate dissolution processes associated with this decomposition may result in sequestration of seagrass aboveand below-ground carbon into the bicarbonate pool (2.4 $\times 10^{13} \mathrm{gC} \mathrm{yr}^{-1}$ ), where it has a residence time on the order of tens of thousands of years.
\end{abstract}

KEY WORDS: Primary productivity - Remote sensing • Ocean color · Inherent optical properties · Benthic reflectance · Bahamas · Grapestone sediment written consent of the publisher

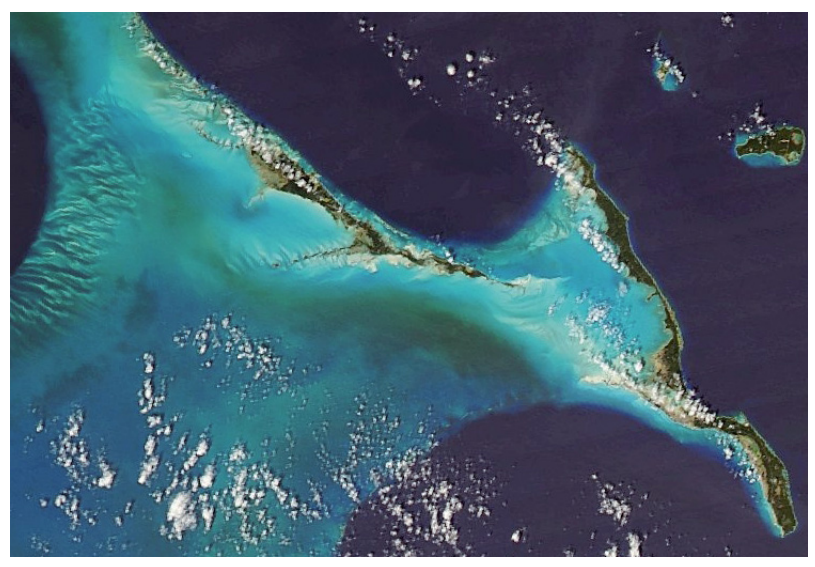

Pseudo-true color image from the MODIS Aqua sensor at $250 \mathrm{~m}$ resolution shows the multihued reflections from shallow waters in the southern Bahamas.

Image: C. Buonassissi and NASA Ocean Biology Processing Group

\section{INTRODUCTION}

In 1918, Johannes Petersen published the first spatial estimates of seagrass production along a $7000 \mathrm{~km}^{2}$ basin off the coast of Denmark and reported that it was more than 4 times the quantity of hay annually produced by Danish fields and meadows (Petersen 1918). Despite this early effort, global assessments of productivity from seagrass and other benthic producers remain elusive and their contributions to regional and global biogeochemical cycles remain poorly quantified (Smith 1981, Short \& Wyllie-Echeverria 1996).

(c) Inter-Research $2010 \cdot$ www.int-res.com 
Benthic producers can have relevance to climate studies both in terms of the amount of productivity and the fate of that productivity. For example, seagrasses may cover roughly $6 \times 10^{5} \mathrm{~km}^{2}$ of the global seafloor and their net primary production (NPP) is estimated to be $0.5 \mathrm{PgC} \mathrm{yr}^{-1}$ (Duarte \& Cebrian 1996, Mateo et al. 2006). This reflects roughly $1 \%$ of NPP of the ocean's phytoplankton (Longhurst et al. 1995). The role benthic producers play in both the local ecology and biogeochemical cycles, however, also depends on how much production is left unremineralized by herbivores and decomposers to accumulate in the seabed (Short 1980, Mateo et al. 2006). Along the Exumas portion of the Great Bahama Bank (GBB), highly productive mats of negatively buoyant benthic macroalgae may be transported into the deep Tongue of the Ocean in pulsed exports exceeding $7 \times 10^{10} \mathrm{~g}$ of carbon (Dierssen et al. 2009b). Such events are equivalent to the daily carbon flux of phytoplankton biomass in the pelagic tropical North Atlantic, and 0.2 to $0.8 \%$ of daily carbon flux from the global ocean. Moreover, different species of seagrass may play different ecological roles based on whether the majority of the biomass accumulates locally within the bed or is transported out of the ecosystem (Zieman et al. 1979, Burdige \& Zimmerman 2002, Burdige et al. 2008). Hence improved methods for quantifying largescale benthic ecology are warranted.

Quantifying productivity of benthic ecosystems is challenging due to the high degree of fine-scale variability in the seafloor features in many environments ( $\mathrm{cm}$ to $\mathrm{m}$ scale) and the limited perspective available from traditional in situ sampling methods. Remote sensing of benthic environments from space offers the potential for filling in this gap (reviewed in Dekker et al. 2006, Phinn et al. 2008); however, such methods require considerable in situ measurements to develop approaches to differentiate among types of benthic producers (seagrass, algal-covered sand, sediment) and to differentiate the optical signatures of the water column and the benthos.

The GBB is an ideal experimental platform to develop and test remote sensing approaches for estimating NPP of benthic habitats. The water is consistently shallow across the bank ( 3 to $10 \mathrm{~m}$ ) and large regions of 'green' seafloor are observable from space (Fig. 1). Moreover, the water overlying much of the GBB is relatively oligotrophic, without significant water column phytoplankton biomass. Water column optical properties are primarily dominated colored dissolved organic matter produced by benthic organisms, such as seagrass (Boss \& Zaneveld 2003, Otis et al. 2004). However, on the western portion of the GBB near Andros Island, fine lime mud and pellet mud sediments can be periodically suspended into the water column, produc- ing 'whitings' that are visible from space (Robbins et al. 1997, Dierssen et al. 2009a). These turbid, wind-driven whiting events can obscure the benthos from view, but cover only a relatively small area per episode. Hence, the expansive GBB is, for the most part, optically shallow, in that reflectance of the seafloor contributes to the reflected light measured by a satellite or aircraft.

As with phytoplankton in the open ocean, variations in benthic environments change the ocean color expressed at the sea surface, which can be exploited to estimate the distributions of the respective seafloor constituents. Many methods have been developed for conducting remote sensing of seagrasses and other benthic producers (reviewed by Kelly 1980, Dekker et al. 2006). Such approaches vary depending on the spectral resolution of available imagery and can involve look-up tables (Dierssen et al. 2003, Louchard et al. 2003, Mobley et al. 2005), hyperspectral optimization techniques (Lee et al. 1999), and other radiative transfer-based approaches (Dekker et al. 2005). The amount and spectral shape of reflected light is influenced by water depth, water column optical properties, and reflectance signatures of the underlying benthos (Armstrong 1993, Maritorena et al. 1994). However, methods depend on the spectral resolution available from a sensor (Phinn et al. 2008), in addition to the spatial resolution, and the ability to retrieve calibrated and atmospherically corrected imagery over the optically shallow region.

In the present study, field data were used to develop an ocean color remote sensing model to characterize the benthic habitats of the GBB. Using a radiative transfer-based approach, the distribution of broad categories of primary producer habitats (seagrass, algae, and sand) were estimated from variations in remotely sensed ocean color, from hues of light blue (primarily sand) to green (vegetated), across the GBB and combined with empirical relationships between primary producer abundance and benthic productivity to estimate the contribution of these highly productive shallow seas to the global carbon cycle.

\section{MATERIALS AND METHODS}

The present study was conducted on the GBB in March 2004 aboard the RV 'Walton Smith' (Fig. 1). Twenty-five stations were sampled across the northern portions of GBB near Andros and along the Exumas Archipelago (Fig. 1). At each station, divers were deployed in the water to survey the site, quantify seagrass densities if present, and collect sediment cores. Water column optical and physical measurements and hyperspectral reflectance measurements were con- 


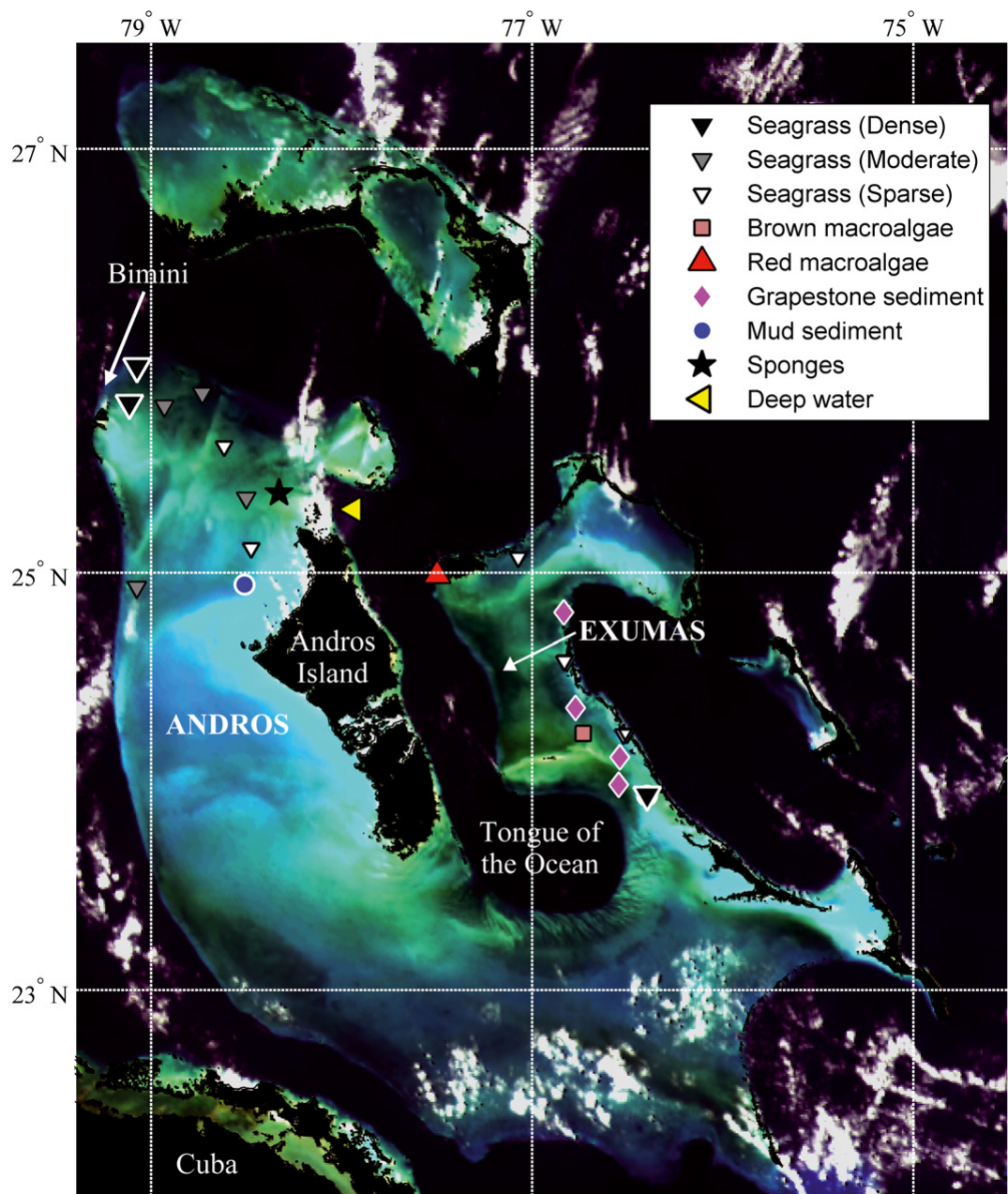

Fig. 1. SeaWiFS true color image (6 March 2004) of the tropical West Atlantic reveals extensive areas of green and blue-colored optically shallow water across the entire Great Bahama Banks. Dominant benthic type at each field station is identified in the key

ducted in situ. Sediment, seagrass, and macroalgae samples were collected by divers and analyzed further in the laboratory. Reflectance measurements were conducted on the sediment cores collected at all stations. Oxygenic photosynthesis and respiration was measured at a subset of the stations representing the different habitats: turtle grass leaves of all ages present within a shoot were analyzed with epiphytes from Stns WS12, WS13, WS16, and WS20; the macroalgae Colpomenia sp. was analyzed from Stn WS7 where it was found in organized benthic windrows caused by Langmuir circulation (Dierssen et al. 2009b); grapestone sediments with extensive microalgal cover were analyzed from Stn WS6. Seagrass productivity was also estimated from in situ leaf growth rates and compared to field measurements conducted in 2002 and 2003 near Lee Stocking Island, Bahamas (Dierssen et al. 2003).
Optical measurements. A variety of optical measurements were conducted to characterize how the water column and seafloor absorb, scatter, and reflect light. The reader is referred to Mobley (1994) for a more detailed characterization of optical terminology. An ac-9 Plus package (WET Labs) was deployed at each station to measure light absorption and attenuation of the water column at a fixed depth of 2 to $3 \mathrm{~m}$ below the sea surface. Salinity and temperature were measured using an SBE 19 (Sea-Bird Electronics) integrated into the package. The particulate and dissolved absorption and attenuation coefficients, $a_{\text {pg }}$ and $C_{\mathrm{pg}}$, respectively, were corrected for temperature, salinity, and scattering effects (Dierssen et al. 2009a). Drift offsets were obtained from a post-cruise clean water calibration. Total particulate scattering $\left(b_{\mathrm{p}}\right)$ was calculated as the difference between $c_{\mathrm{pg}}$ and $a_{\mathrm{pg}}$, assuming negligible scattering from dissolved material. The particulate backscattering coefficient $\left(b_{\mathrm{bp}}\right)$ refers to all the photons that have been redirected in the backward direction due to scattering from particles in the water and, to a first order, is positively correlated to the total concentration of particles in the water (reviewed in Stramski et al. 2004). The ECOVSF (WET Labs) provided backscattering measurements at 3 angles $(100,125$, and $\left.150^{\circ}\right)$ and 3 wavelengths $(470,532$, and $650 \mathrm{~nm})$. Data were corrected for light attenuation effects using concurrent $a c-9$ data and extrapolated from 90 to $180^{\circ}$ using a third-order polynomial. The backscattering ratio $\left(\tilde{b}_{\mathrm{bp}}\right)$ was calculated as the ratio of $b_{\mathrm{bp}}$ to $b_{\mathrm{p}}$. Remote sensing reflectance $\left(R_{\mathrm{rs}}\right)$ represents the spectral distribution of light emerging from the sea surface normalized to that incident upon the sea surface and was measured at each station using a Field Spec Pro ${ }^{\mathrm{TM}}$ VNIR-NIR1 portable spectrometer system (Analytical Spectral Devices). A sequence of measurements was made with an $8^{\circ}$ foreoptic focused at a 40 to $45^{\circ}$ angle sequentially on a gray plaque, sea surface, and sky. The parameter $R_{\mathrm{rs}}$ was calculated as the water-leaving radiance normalized to downwelling irradiance reaching the sea surface following Mobley et al. (1999). Values of $R_{\mathrm{rs}}$ exclude photons which have reflected off the sea surface and do not penetrate the water surface (i.e. sun glint). Residual reflected sky radiance was corrected using reflectance differences between 715 and $735 \mathrm{~nm}$, an approach specifically developed for coastal waters (Gould et al. 2001). 
Seagrass morphology, density, and growth. Shoot density of the seagrasses Thalassia testudinum (turtle grass), Syringodium filiforme (manatee grass), and Halodule wrightii (shoal grass) were estimated at each station using 15 to 20 randomly located $0.04 \mathrm{~m}^{2}$ quadrats within a $20 \mathrm{~m}$ radius around a central buoy, spanning roughly $1000 \mathrm{~m}^{2}$ at each station. One shoot of each species (if present) was collected randomly from each quadrat and the length (nearest $\mathrm{mm}$ ) and width (nearest $0.01 \mathrm{~mm}$ ) of each leaf was measured in the laboratory. Leaf area index (LAI) was estimated from leaf morphometrics and shoot density counts as the average one-sided leaf area per surface area $\left(\mathrm{m}^{2}\right)$ of substrate (Zimmerman 2003).

Reflectance of individual turtle grass leaves were measured in the laboratory using a Shimadzu UV2101PC scanning spectrophotometer fitted with an integrating sphere. Sediment cores were collected by divers and the surface reflectance was estimated in the laboratory using the Field Spec-Pro with the bare fiber optic probe positioned over the illuminated sample and referenced against a white spectralon plaque $(99.9 \%$ reflectance) positioned similarly. For each core, 5 different spectra were recorded and averaged. Because of the way light refracts as it transfers through an air-water interface, these measurements approximate the spectral shape of reflectance, but the absolute spectral magnitude may vary somewhat from the reflectance of submerged cores.

Leaf growth rates were measured at 2 stations populated by turtle grass. One shoot from each quadrat was marked with a 20 gauge hypodermic needle at the top of the leaf sheath (Zieman \& Wetzel 1980) and tagged with a length of pink flagging tape for subsequent identification. The shoots were collected $2 \mathrm{wk}$ after marking and the new growth of each leaf was measured. NPP was estimated for each site as the product of LAI and leaf growth rate $\left(\% \mathrm{~d}^{-1}\right)$ and converted to a mass-specific rate using measured ratios for shoot fresh weight (FW) and dry weight (DW), which ranged from 0.09 to $0.22 \mathrm{~g} \mathrm{DW} \mathrm{g}^{-1} \mathrm{FW}$. Average conversions of $0.05 \mathrm{~g} \mathrm{FW} \mathrm{cm}^{-2}, 0.16 \mathrm{~g} \mathrm{DW} \mathrm{g}^{-1} \mathrm{FW}$, and $0.35 \mathrm{~g} \mathrm{C} \mathrm{g}^{-1} \mathrm{DW}$ were used (Zimmerman 2003).

Primary producer metabolism. Oxygenic photosynthesis and respiration of turtle grass leaves, brown algae Colpomenia sp. thalli, and grapestone sediments were measured polarographically in clear glass waterjacketed incubation chambers ( $5 \mathrm{ml}$ volume). For the turtle grass leaves, 3 replicates of the different leaf ages were conducted at Stn WS04, 2 replicates at Stns WS12 and WS13, and 1 measurement for each leaf age at Stns WS02, WS03, WS16, and WS20. Three replicates were conducted for Colpomenia sp. and only 1 measurement for the grapestone sediment. Temperature inside the chambers was maintained at $22^{\circ} \mathrm{C}$ and elec- trode drift was measured in chambers filled with airsaturated seawater prior to the addition of each sample. Respiration of each sample was measured in the dark using air-saturated seawater. At the end of the respiration period, $\mathrm{O}_{2}$ content of the incubation medium was further reduced to about $50 \%$ of air saturation by bubbling with a gas mixture of $\mathrm{CO}_{2}\left(350 \mathrm{ppm}\right.$ ) and $\mathrm{N}_{2}$ (balance) before commencing photosynthesis measurements The light-saturated rate of photosynthesis $\left(P_{\mathrm{m}}\right)$ was measured by exposing each sample to $\sim 600 \mu \mathrm{mol}$ quanta $\mathrm{m}^{-2} \mathrm{~s}^{-1}$ of white light provided by a fiber optic light source using a variable intensity incandescent lamp (Dolan-Jenner Industries, Fiber-Lite Series 180). Incubation irradiance was measured using a factorycalibrated quantum irradiance meter (Biospherical Instruments, QSL-100). Sample weights were determined after drying at $65^{\circ} \mathrm{C}$ for $\sim 10 \mathrm{~d}$. NPP was estimated assuming photosynthesis was light saturated for $12 \mathrm{~h} \mathrm{~d}^{-1}$ and the photosynthetic quotient $\left(\mathrm{O}_{2}: \mathrm{CO}_{2}\right)$ was 1.2 , following the procedure outlined in Dierssen et al. (2009b). Seagrass leaves were assumed to comprise $0.05 \mathrm{~g} \mathrm{FW} \mathrm{cm}^{-2}$ of leaf area, which was derived from turtle grass samples collected at Lee Stocking Island (Zimmerman 2003). The drifting macroalga Colpomenia sp. was determined to be 3 to $10 \mathrm{~cm}$ in thickness distributed in ordered windrows (Dierssen et al. 2009b) and assumed to be $2 \mathrm{~cm}$ in thickness averaged over non-windrow area without windrows. The macroalgae was negatively buoyant, but the density was conservatively assumed to be that of seawater $\left(1025 \mathrm{~kg} \mathrm{~m}^{-3}\right)$.

Image processing. A full resolution $(1 \mathrm{~km})$ Sea-viewing Wide Field-of-View (SeaWiFS) Level 1A Local Area Coverage image from 6 March 2004 provided a relatively cloud-free view of the GBB. Standard atmospheric correction routines for SeaWiFS, which were developed for optically-deep open ocean water, cannot be applied accurately to the optically shallow GBB. Consequently, $R_{\mathrm{rs}}$ was derived at each pixel in the image by applying an iterative scheme to first process the image using the SeaWiFS multiple-scattering atmospheric correction algorithm (Gordon 1997). The atmospheric correction scheme from neighboring deep water was identified and the entire image was then reprocessed with SeaWiFS Data Analysis System using a fixed aerosol model for the region. This type of atmospheric correction is only an approximation of the atmospheric properties over shallow water. Errors in aerosols, whitecaps, and sun glint estimated over deep water can lead to consistent biases in retrieved reflectances over shallow water. A linear correction was derived for each wavelength where the offset represents errors due to path radiance and the slope represents errors in the transmission of water-leaving radiance through the atmosphere (Gordon 1997). Linear regression was conducted with $R_{\mathrm{rs}}$ derived from 
the SeaWiFS sensor and in situ measurements from a subset of 6 stations considered to be consistent at $\mathrm{km}$ scales from our field observations. Some stations, for example, had patchy distributions of seagrass and were excluded from this analysis. The image was then georeferenced and warped based on a complete geometry model of the earth and satellite orbit. Estimates of bottom reflectance, $R_{\mathrm{B}}$, were modeled from the $R_{\mathrm{rs}}$ (in situ values used for model development or satellite-derived values for model application) following the look-up table approach outlined in Dierssen et al. (2003), as discussed further in the 'Results'.

\section{RESULTS}

\section{Benthic characterization}

We encountered a variety of benthic habitats across the study area, including those predominantly comprised of seagrass, benthic macroalgae, and sediment microalgae. Seagrass meadows (Fig. 1) were concentrated along the outer perimeter of the bank in areas experiencing regular tidal exchange with Atlantic waters. Stations to the west of Andros Island were comprised of fine pellet muds, but also contained sparse distributions of seagrass. Along the Exumas, 4 different types of benthic communities were found: seagrass, brown macroalgae, red macroalgae, and microalgae associated with grapestone sediment. Bahamian grapestone is a coarse sediment produced by microbial colonization and cementation of recrystallized ooids that gives the aggregated grains the appearance of a bunch of grapes (Winland \& Matthews 1974). The algal content of grapestone biofilms can be highly variable, with chlorophyll concentrations ranging from 2 to $10 \mathrm{\mu g} \mathrm{g}^{-1}$ (Stephens et al. 2003). At stations sampled along the Exumas, the grapestone color ranged from light to dark green, indicative of variability in microalgal density. The phaeophyte Colpomenia sp. was observed at the westernmost station sampled on the Exumas in a series of windrows ordered along the seafloor by wind-driven helical (Langmuir) circulation (Monahan 1993, Dierssen et al. 2009b).

LAI provided a quantitative measure of the seagrass abundance that incorporated both the shoot density and leaf morphometric data (height and width). The highest LAI on the GBB $(3.7 \pm 0.4)$ was measured at a station near Bimini Island (WS01, $5.2 \mathrm{~m}$ depth) containing a mixture of the cylindrically bladed manatee grass and flat-bladed turtle grass (Table 1). Other dense seagrass meadows comprised of both species (LAI 1.5 to 2.2) were

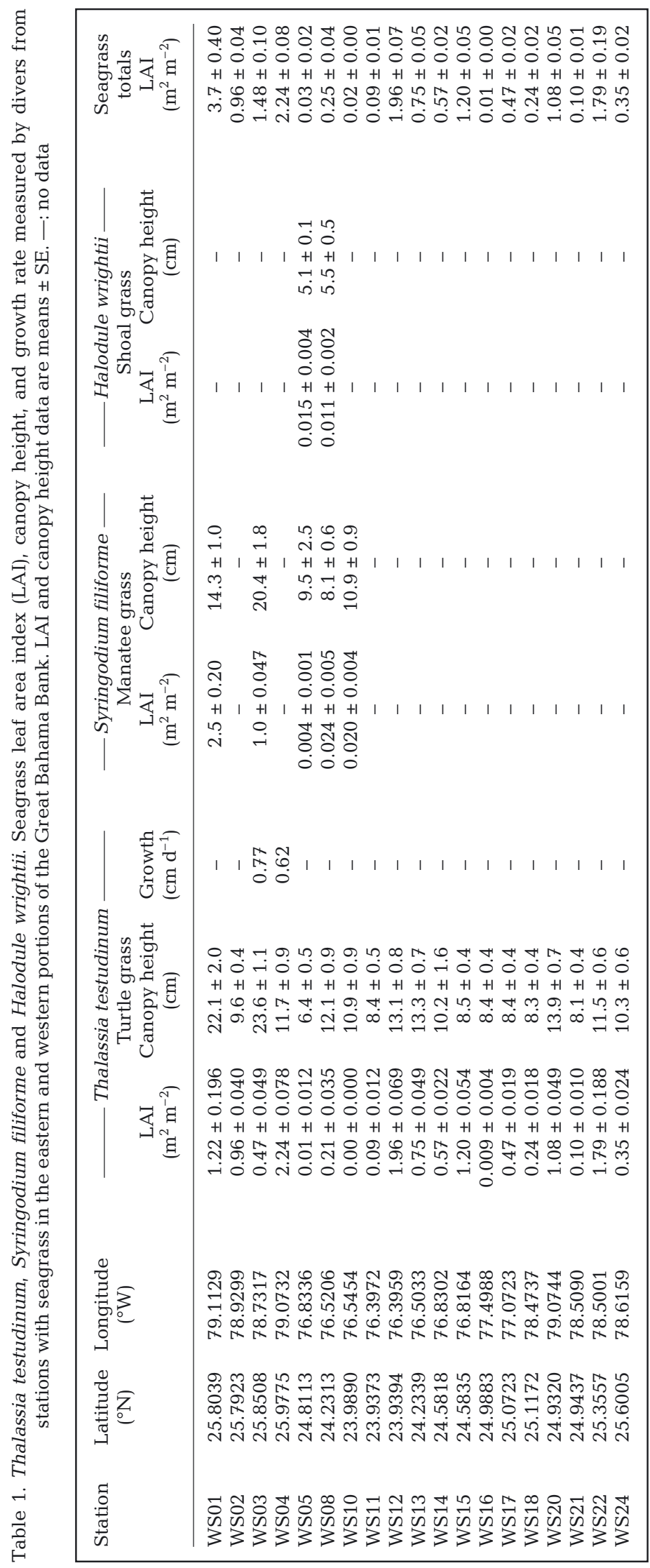


found further north in this area at depths up to $10 \mathrm{~m}$ (Fig. 1). Along the Exumas, meadows of turtle grass occurred primarily at 3 to $5 \mathrm{~m}$ depth in water bordering the channels near the islands with LAI ranging up to 2 . At 2 stations close to the Exuma Islands, shoal grass was found interspersed with turtle grass. Sparse distributions of turtle grass were found directly west of Andros Island growing in the mud sediment (LAI < 0.2). Isolated patches of dense turtle grass occurred sporadically along Andros (WS22) surrounded by extensive flats of white sand, sponges, and isolated coral heads.

Total LAI for all species of seagrass could be predicted by total shoot density (shoots $\mathrm{m}^{-2}$ ), which explained over $80 \%$ of the variability in the data (Fig. 2A). Although the regression was heavily influenced by one station with very high LAI, the general relationship between shoot density and LAI was strongly linear,
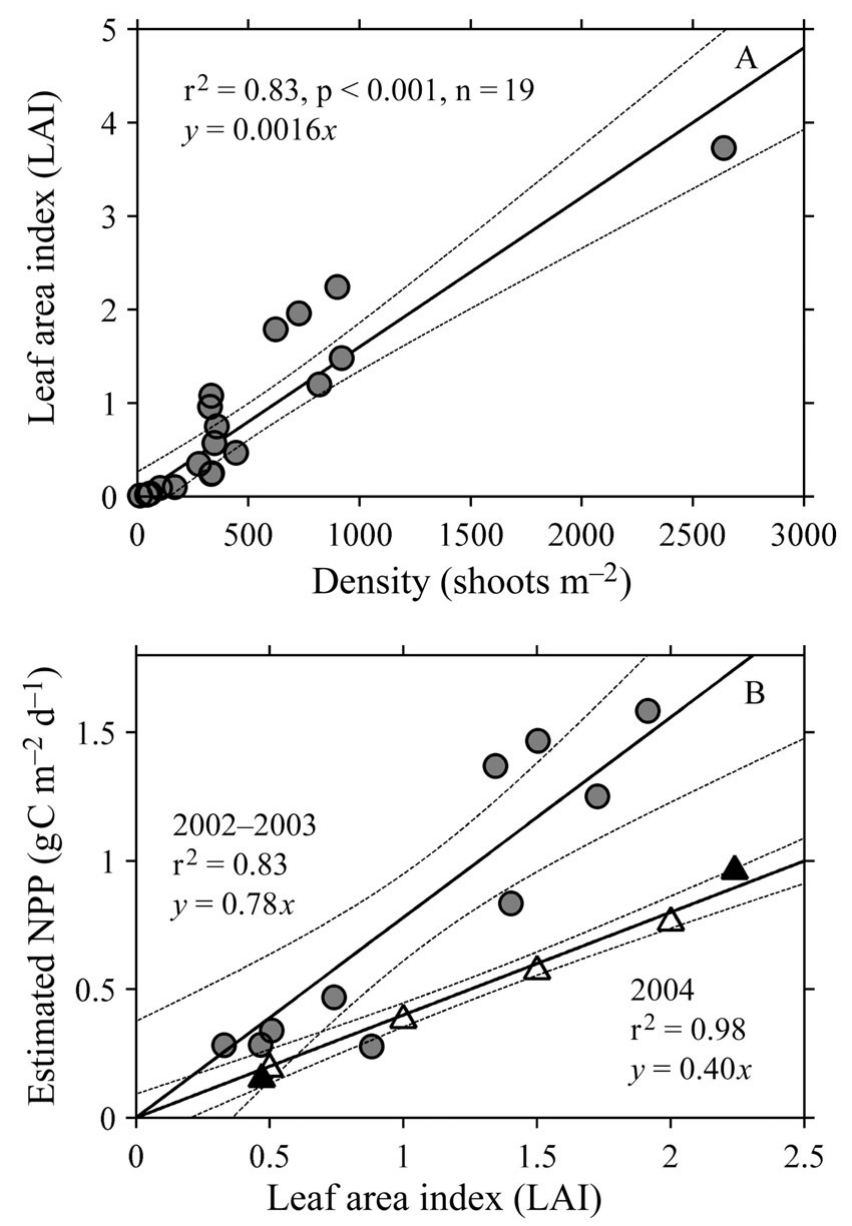

Fig. 2. (A) Relationship between seagrass shoot density and estimated leaf area index (LAI) ranging from 0 to 3.5. (B) Seagrass LAI and above-ground net primary production (NPP) determined in 2002-2003 near Lee Stocking Island, Bahamas, from in situ leaf growth rates (O), in 2004 at northern Bimini stations from in situ growth rates ( $\mathbf{\Delta})$, and in 2004 from laboratory metabolism measurements $(\Delta)$. Dashed lines represent $95 \%$ confidence intervals for the regression despite the fact that different stations contained different mixtures of seagrass species. The residual variability among stations was due to differences in shoot morphometry, including leaf length and width. For both seagrass species, canopy heights were significantly taller at the Andros stations compared to the Exumas. Shoot leaf area of turtle grass, calculated as the sum of the one-sided area of all leaves on each shoot, averaged $29 \mathrm{~cm}^{2}$ shoot $^{-1}$ for Andros stations and only $15 \mathrm{~cm}^{2}$ shoot $^{-1}$ for the Exumas populations. Shoot leaf area of manatee grass was $11 \mathrm{~cm}^{2}$ shoot $^{-1}$ at Andros stations and only $3 \mathrm{~cm}^{2}$ shoot $^{-1}$ at the Exumas. No trend was evident between the canopy height and depth of occurrence $\left(r^{2}=0.17, p>0.05\right.$, data not shown).

The ratio of gross photosynthesis to respiration for turtle grass averaged $5.19 \pm 2.74$ (Table 2 ), resulting in NPP ranging from $0.2 \pm 0.1 \mathrm{gC} \mathrm{m}^{-2} \mathrm{~d}^{-1}$ for relatively sparse seagrass with an LAI of 0.5 up to $0.8 \pm 0.3 \mathrm{gC}$ $\mathrm{m}^{-2} \mathrm{~d}^{-1}$ for dense seagrass with an LAI of 2.5. NPP from in situ leaf growth rates from 2 Andros stations (WS03 and WS04) measured over a $2 \mathrm{wk}$ period were similar in magnitude (Fig. 2B, solid triangles) and followed the relationship: $\mathrm{NPP}=0.4 \times \mathrm{LAI}$.

In comparison, NPP estimated in May-June 2002 and 2003 near Lee Stocking Island on the Exumas (Dierssen et al. 2003) was nearly 2-fold higher (slope of 0.78 ) than 2004 rates (Fig. 2B, circles). This higher rate could be due to differences between spring and summer sampling and greater exchange of nutrients on the Exumas compared to Andros.

Rates of NPP for benthic algae were quite variable depending on the taxon. The highest metabolism and corresponding NPP was measured for the phaeophyte Colpomenia sp. found growing rapidly on the mid-portion of the Exumas. Dense accumulations of this brown macroalga were found as unattached free-drifting mats tumbling along the bottom with currents believed to be generated by Langmuir circulation (Dierssen et al. 2009b). From photosynthesis estimates on individual thalli, we estimated NPP to be $18 \pm 4.4 \mathrm{~g} \mathrm{C} \mathrm{m}^{-2} \mathrm{~d}^{-1}$. However, this estimate does not incorporate self-shading and spectral changes in light availability within the drifting mats (Vergara et al. 1997, Brush \& Nixon 2003), which may serve to diminish NPP somewhat.

In contrast, grapestone sediments containing thin algal biofilms were barely net autotrophic, with rates of $0.005 \mathrm{~g} \mathrm{C} \mathrm{m}^{-2} \mathrm{~d}^{-1}$. NPP of red algae and grapestone with dense biofilm was not measured directly. Benthic microalgae within sediment from the seagrass meadows may also contribute to NPP (MacIntyre et al. 1996) but was not measured directly in the present study. Around Lee Stocking Island Bahamas, sediment chlorophyll a (chl a) concentrations were 3-fold higher in dense turtle grass beds ( 3 to $4 \mu \mathrm{g} \mathrm{g}^{-1}$ sediment) compared to adjacent sediment (Stephens et al. 2003). 
Table 2. Thalassia testudinum, Colpomenia sp. and grapestone sediment. Net primary productivity (NPP) of benthic producers measured across the Great Bahama Bank. Leaf area index (LAI) is the area $\left(\mathrm{m}^{2}\right)$ of 1-sided seagrass leaf per $\mathrm{m}^{2}$ seafloor. Pg:R: ratio of gross production to respiration; DW: dry weight

\begin{tabular}{|c|c|c|c|c|}
\hline Producer & $\begin{array}{l}\text { Gross oxygen evolution, } \mathrm{Pg} \\
\left(\mu \mathrm{mol} \mathrm{O} \mathrm{O}_{2} \mathrm{~min}^{-1} \mathrm{~g} \mathrm{DW}^{-1}\right)\end{array}$ & Pg:R & $\begin{array}{l}\text { Areal average } \\
\left(g^{\mathrm{D} \mathrm{DW} \mathrm{m}} \mathrm{m}^{-2}\right)\end{array}$ & $\begin{array}{c}\mathrm{NPP} \\
\left(\mathrm{gC} \mathrm{m}^{-2} \mathrm{~d}^{-1}\right)\end{array}$ \\
\hline Seagrass Thalassia testudinum & $0.78 \pm 0.28(n=23)$ & $5.19 \pm 2.74$ & & \\
\hline LAI 0.5 & & & 50 & $0.17 \pm 0.11$ \\
\hline LAI 1.0 & & & 100 & $0.35 \pm 0.13$ \\
\hline LAI 1.5 & & & 150 & $0.52 \pm 0.19$ \\
\hline LAI 2.0 & & & 200 & $0.69 \pm 0.25$ \\
\hline Macroalgae Colpomenia sp. & $2.20 \pm 0.24(\mathrm{n}=3)$ & $4.71 \pm 0.59$ & 2050 & $18 \pm 4.4^{\mathrm{a}}$ \\
\hline Grapestone algae & $0.056(\mathrm{n}=1)$ & 2.12 & 205 & 0.005 \\
\hline
\end{tabular}

\section{Optical properties}

In order to interpret a remote sensing signal derived from the benthic primary producers, water column optical properties were measured in the surface waters at all benthic stations, as well as in surface waters of the Tongue of the Ocean (>1000 m). Consistent with past studies and visual observations by the divers, the absorption $\left(a_{\mathrm{pg}}\right)$ and attenuation $\left(c_{\mathrm{pg}}\right)$ coefficients were generally low across the entire region, indicating high water clarity (Fig. 3A,B). The spectral shape of the absorption coefficient was consistent with the presence of colored dissolved organic matter and few phytoplankton sus- pended in the water column (Boss \& Zaneveld 2003). Water from the Tongue had considerably lower absorption and attenuation coefficients compared to the bank. Andros also had higher $c_{p g}$ than either the Exumas or the Tongue, likely due to the presence of non-absorbing 'white' calcite fine sediment particles suspended in the water column (Shinn et al. 1989, Dierssen et al. 2009a). We assumed that $a_{\text {pg }}$ was primarily due to dissolved absorption $\left(a_{g}\right)$ and subtracted this from the $c_{\mathrm{pg}}$ values to obtain an estimate of light attenuation of particulates alone, $c_{\mathrm{p}}$. The hyperbolic wavelength spectra of $c_{p}$ for Andros, Exumas, and the Tongue, respectively, were $0.95 \pm 0.21,0.98 \pm 0.22$, and 0.8 ( 1 measurement only).
Fig. 3. Mean inherent optical properties $( \pm 1$ $\mathrm{SD)}$ measured at stations from Andros, Exumas and the Tongue of the Ocean: (A) absorption by particulate and dissolved material $\left(a_{\mathrm{pg}}\right)$; (B) attenuation by particulate and dissolved material $\left(C_{\mathrm{pg}}\right) ;(\mathrm{C})$ particulate backscattering $\left(b_{\mathrm{bp}}\right)$; and (D) backscattering ratio $\left(\tilde{b}_{\mathrm{bp}}\right)$
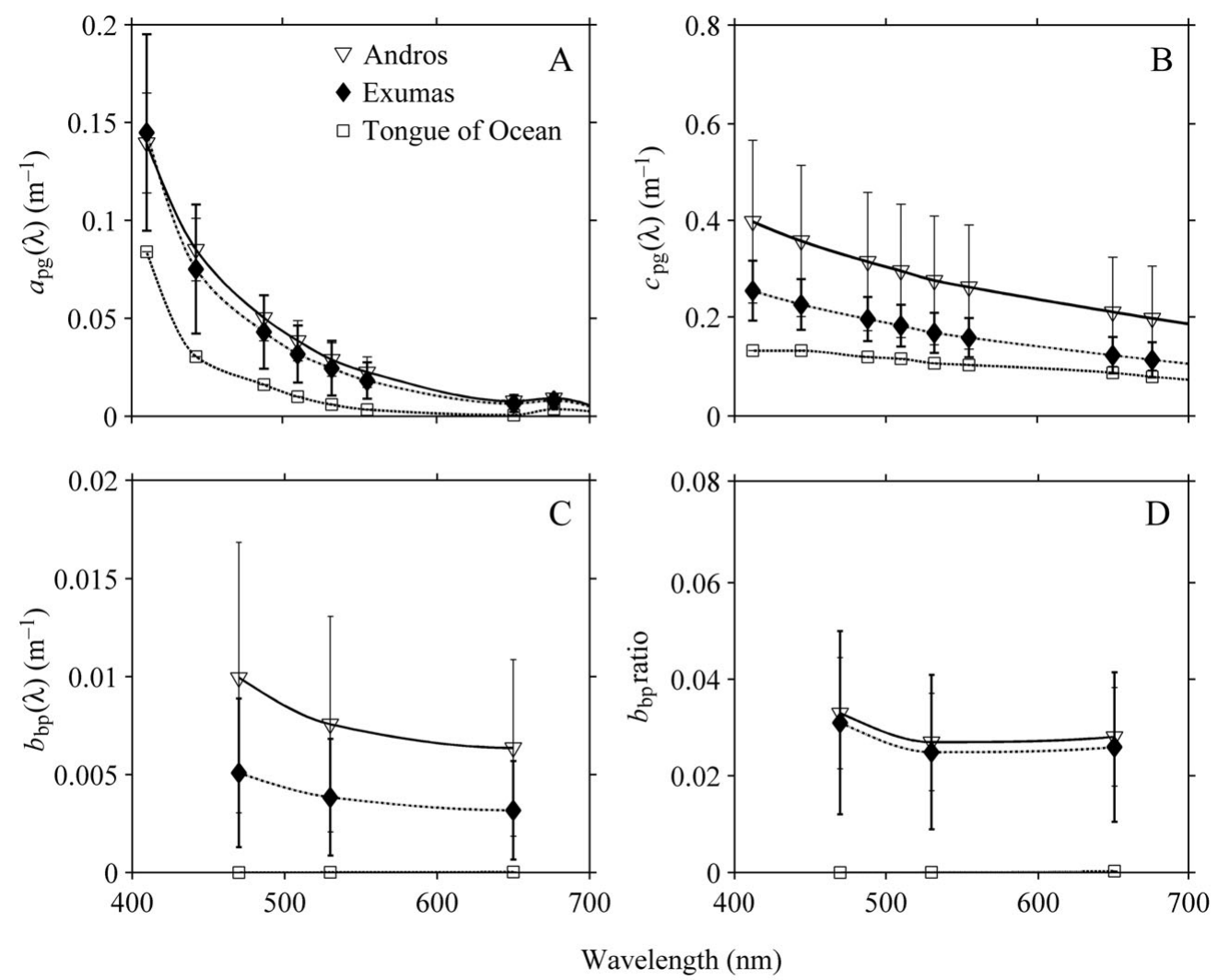
The particulate backscattering data revealed a similar pattern. Levels of $b_{\mathrm{bp}}$ from stations west of Andros were twice as high as stations near the Exumas (Fig. 3C), indicative of more suspended sediment on the western arm of the GBB. This difference was likely due to the larger sediment grains found along the Exumas which were less prone to resuspension (Hu 2007, Dierssen et al. 2009a). Water from the Tongue was so devoid of particles that measurements of $b_{\mathrm{bp}}$ were below the limit of detection for the instrument (data not shown). The ratio of backscattering to total scattering $\left(\tilde{b}_{\mathrm{bp}}\right)$ was high and consistent between the Andros and Exumas regions (Fig. 3D). Measurements averaged $\sim 0.028$ across all stations and no significant wavelength dependence was observed. Such high values are consistent with the presence of minerogenic parti- cles (i.e. suspended sediment) rather than biogenic particles (i.e. phytoplankton). Levels of $\tilde{b}_{\mathrm{bp}}$ reached as high as 0.05 during an intense resuspension events or 'whiting' which occurred at WS19 west of Andros Island (Dierssen et al. 2009a). The estimated bulk index of refraction calculated according to Twardowski et al. (2001) on the GBB was 1.16, consistent with the presence of inorganic minerogenic sediment particles and few organic phytoplankton.

Sea spectral reflectance used for remote sensing studies $\left(R_{\mathrm{rs}}\right.$, i.e. water-leaving radiance normalized to incident downwelling irradiance) provided an indicator of the water color across the visible spectrum at each station. Levels of $R_{\mathrm{rs}}$ from selected locations at $5 \mathrm{~m}$ depth revealed quite different spectral magnitudes and shapes depending on the seafloor composition (Fig. 4A). Grape-
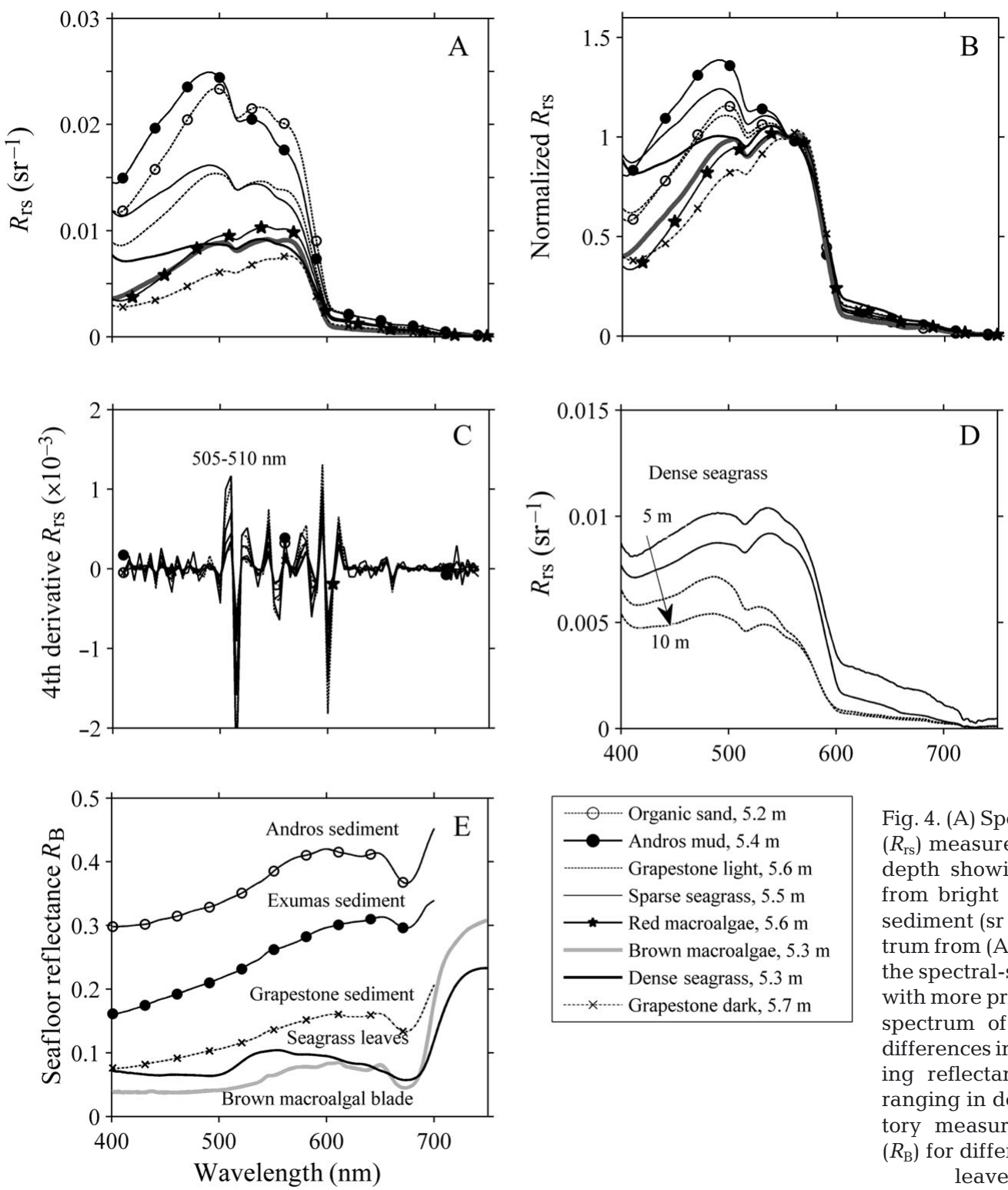

Fig. 4. (A) Spectral remote sensing reflectance $\left(R_{\mathrm{rs}}\right)$ measured at 8 stations with $\sim 5 \mathrm{~m}$ water depth showing the decrease in magnitude from bright sand to dark green grapestone sediment ( $\mathrm{sr}=$ steradian). (B) The same spectrum from (A) normalized to $R_{\mathrm{rs}}(555)$ showing the spectral-shift from blue- to green-peaked with more productive benthos. (C) Derivative spectrum of $R_{\mathrm{rs}}$ showing wavebands with differences in spectral slope. (D) Remote sensing reflectance over dense seagrass beds ranging in depth from 5 to $10 \mathrm{~m}$. (E) Laboratory measurements of benthic reflectance $\left(R_{\mathrm{B}}\right)$ for different types of sediment, seagrass leaves, and macroalgal blades 
stone sediment with a green biofilm had the lowest $R_{\mathrm{rs}}$ and peaked in the green at $\sim 570 \mathrm{~nm}$. Stations comprised of red and brown macroalgae had slightly higher $R_{\mathrm{rs}}$ but similar spectral shapes. Dense seagrass beds had a similar magnitude in the green (500 to $570 \mathrm{~nm}$ ), but appeared to reflect more light in the blue portion of the spectrum (400 to $500 \mathrm{~nm}$ ) than the other benthic producers. Remotely sensed reflectance from organic sand and Andros mud were both $\sim 5$ times greater than $R_{\mathrm{rs}}$ from the productive benthic habitats, including grapestone sediment with microalgal biofilm. Moreover, the spectra peaked at $500 \mathrm{~nm}$ compared to the 550 to $570 \mathrm{~nm}$ peak observed for the other spectra.

When the spectra were normalized to $R_{\mathrm{rs}}$ at $555 \mathrm{~nm}$, shape differences between the various benthic types were readily observed (Fig. 4B). At $5 \mathrm{~m}$ depth, the reflectance peaks of high productivity stations were green-shifted relative to low productivity stations. Fourth derivatives of the spectra (Fig. 4C) revealed spectral regions that could potentially be used to differentiate different benthic types with high signal-tonoise imaging spectroscopy. Subtleties in spectral shape were most apparent in the green region of the spectrum with differences observed at 505 to 510, 515, 525, and $550 \mathrm{~nm}$.

Highly productive dense seagrass meadows were found growing at depths $>10 \mathrm{~m}$ at the north end of Andros (WS03 and WS04) and the reflectance signature was dominated by blue light rather than green as the influence of water column on $R_{\mathrm{rs}}$ increased with depth (Fig. 4D). From space, therefore, the deep seagrass beds appeared more blue than green. In addition, reflectance in the red portion of the spectrum $(600$ to $700 \mathrm{~nm}$ ) was also 2- to 3-fold greater at the shallower stations, because more of the red light reflected from seafloor reaches the sea surface (Dierssen et al. 2003).

The reflectance of the benthos $\left(R_{\mathrm{B}}\right)$ associated with each station was a combination of differently colored sediments and benthic constituents. Reflectance from seagrass leaves and macroalgae blades measured in the laboratory (Fig. 4E) had low reflectance across most of the visible spectrum. Seagrass leaves were more reflective in the blue and green compared to brown macroalgae, which peaked further in the red at $600 \mathrm{~nm}$. However, the seagrass leaf spectrum does not represent the reflectance from the seagrass canopy, which is a spectral mixture of darker seagrass leaves and brighter sediment that varies depending on the density of the canopy and the brightness of the underlying sand (Zimmerman 2003). Sediment $R_{\mathrm{rs}}$ from different parts of the GBB had a large range in bottom reflectance. Measured $R_{\mathrm{B}}$ from grapestone covered with dense algal biofilm was low in magnitude indicating considerable pigment concentrations. In contrast, sediment from the Exumas was twice as reflective across the visible spectrum. The fine mud sediment from the stations around Andros was even more reflective, peaking at around 0.4 between 550 and $650 \mathrm{~nm}$. Such large differences challenge our ability to estimate benthic properties from multispectral imagery, if bathymetry is unquantified.

\section{Quantifying basin-wide productivity}

Our basic approach for modeling NPP involved estimating $R_{\mathrm{B}}$ from the imagery and then quantifying productivity. To account for absorption and scattering within the water column, $R_{\mathrm{B}}$ was estimated from $R_{\mathrm{rs}}$ using a depth-specific look-up table derived from radiative transfer modeling (Hydrolight, Sequoia Scientific; Mobley 1994) with the measured optical properties of the water column (Dierssen et al. 2003). Average water column optical properties measured during the field campaign (Fig. 3, Exumas) were used in the model and assumed to be generally representative of the GBB. Fig. 5A presents the blue/green sea surface reflectance ratio $\left(R_{\mathrm{rs}}[490]: R_{\mathrm{rs}}[555]\right)$, used to estimate chlorophyll in the optically deep majority of the world's oceans, for stations comprised of different benthic constituents and at different depths. Many of the benthic stations had lower reflective ratios indicative of chlorophyll-containing compounds that absorb blue light. However, reflectance ratios of the deeper seagrass stations (9 to $10 \mathrm{~m}$ depth) mapped into the blue (less productive) region because of the impact of the overlying water column. When the spectral influence of the overlying water column was removed by applying the look-up table approach, seagrass, macroalgae, and grapestone sediment with dense biofilm all grouped together with low green benthic reflectance $R_{\mathrm{B}}(555)$, indicative of high light absorption, while less productive stations had higher modeled $R_{\mathrm{B}}(555)$ (Fig. 5B).

A logarithmic relationship was developed from the in situ data to approximate NPP over 2 orders of magnitude from modeled $R_{\mathrm{B}}(555)$ (Fig. $5 \mathrm{C}, \mathrm{R}^{2}=0.49$, $\mathrm{p}<$ $0.01, \mathrm{n}=26): \log (\mathrm{NPP})=-7.58 R_{\mathrm{B}}(555)+0.65$.

The relationship between benthic reflectance and NPP separated into 3 general groups: high, medium, and low NPP. High NPP was associated with a light absorbing bottom (i.e. dark reflectance); low to nondetectable NPP was associated with low absorbing; and bright bottom reflectances (>3\%) were characteristic of unvegetated sands. The NPP for brown macroalgae Colpomenia sp. was considerably higher than other producers, due in part to its considerable density on the seafloor (Dierssen et al. 2009b). NPP for red algae was assumed to be similar to brown algae, but the density of red algae was estimated by the divers to 

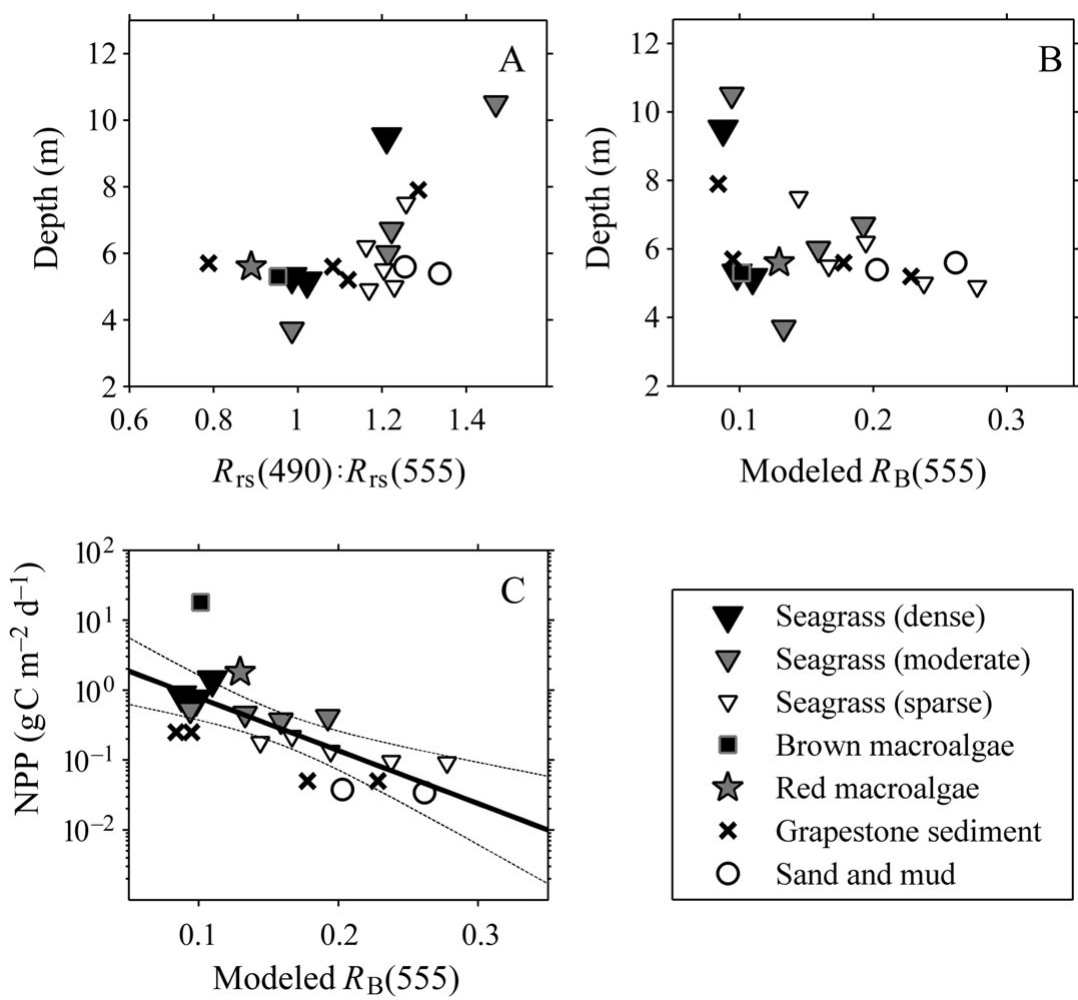

Fig. 5. (A) Ratio of blue to green reflectance was higher for deeper seagrass beds compared to similar density beds at shallower depths. (B) Modeled green bottom reflectance, $R_{\mathrm{B}}(555)$, from the in situ data using a radiative transferbased look-up table. (C) An inverse relationship was found between the modeled $R_{\mathrm{B}}(555)$ and logarithmic net primary productivity (NPP) differentiating regions with high, medium, and low NPP. Dashed lines represent $95 \%$ confidence intervals for the regression

be at least 1 order of magnitude lower than Colpomenia sp. For the stations with grapestone sediment covered with dense biofilm, NPP rates were estimated to be 5 times the NPP measured for the thin biofilm grapestone. Past studies in this region have shown chl a concentrations to be roughly 5 times greater in dense biofilm grapestone compared to thin biofilm grapestone (10.2 versus $1.8 \mu \mathrm{g} \mathrm{g}^{-1}$; Stephens et al. 2003). The present study was limited to NPP measurements of micro- and macroalgae at only a few stations and more comprehensive sampling would be desirable. However, we feel that this approach represents the general relationship between the greenness of the seafloor and the amount of productivity, and captures the large-scale NPP features. The majority of the data points (13 of 22) fell within the $95 \%$ confidence intervals and within a factor of 2 of the measurements.

The logarithmic relationship was applied to SeaWiFS imagery from 6 March 2004, a relatively clear sky satellite overpass from $1 \mathrm{wk}$ prior to the start of the field campaign. Modeling of $R_{\mathrm{B}}(555)$ required accurate knowledge of the bathymetry in order to access the depth-dependent look-up table. Soundings across the bank were digitized (Maptech 2004) and gridded to the same pixel size as the SeaWiFS imagery (Fig. 6A). Deeper water (>8 m) occurred to the north of Andros and on unsampled regions on the southwest of the GBB. Shallow regions occurred to the west of Andros Island and along much of the Exumas $(<5 \mathrm{~m})$. The bathymetry was corrected for tidal height to match bathymetry measured at the sampling stations. Accurate application of the NPP relationship also necessitated appropriate atmospheric correction of the imagery. As shown in Fig. 6B, retrieved estimates of $R_{\mathrm{rs}}$ were similar in both magnitude and spectral shape to measurements made at stations sampled during the field campaign. Values of SeaWiFS-derived $R_{\mathrm{rs}}(555)$ were within $6 \%$ of the measured spectrum of the dark target and $18 \%$ of the bright target.

Satellite-derived NPP across the GBB (Fig. 6C) was low in regions west of Andros Island and high along its northern border. Modeled NPP was in the range of field measurements from stations throughout the bank and generally followed a 1:1 line $\left(\mathrm{r}^{2}=0.64, \mathrm{p}<0.01\right.$, slope $=1.2$, intercept $=0.02$; Fig. 6D). The 95\% confidence intervals fell within a factor of 1.7 to 2.8 over the range of NPP measured. The in situ field stations were sampled at a spatial scale of $\sim 1000 \mathrm{~m}^{2}$ (assuming divers sampled the seafloor randomly within a $20 \mathrm{~m}$ radius around a central buoy) compared to the $1 \times 10^{6} \mathrm{~m}^{2}$ area of an image pixel, and the validation included only those stations with measurable NPP (i.e. not bare sediment) which represented largescale benthic features and had roughly similar bathymetry across the satellite pixel compared to the measured depths. The median NPP across the GBB was $0.38 \mathrm{gC}$ $\mathrm{m}^{-2} \mathrm{~d}^{-1}$. Total NPP aggregated from the pixel estimates across the $95000 \mathrm{~km}^{2}$ of the GBB was $5.0 \times 10^{10} \mathrm{~g} \mathrm{C} \mathrm{d}^{-1}$. Assuming these rates of productivity are representative of biomass and metabolic activity throughout the year,

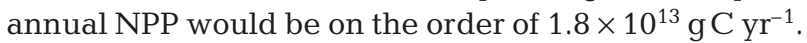

The relative area covered by algae (either macro- or microalgae) versus seagrass (Fig. 7) was estimated by evaluating the retrieved bottom reflectance in blue and green wavelengths $\left(R_{\mathrm{B}}[440]\right.$ and $\left.R_{\mathrm{B}}[555]\right)$. As shown in Fig. 4, the reflectance magnitude at $555 \mathrm{~nm}$ was similar for dense concentrations of all 3 types of benthic producers, but reflectance in the blue wavelengths (440 to $490 \mathrm{~nm}$ ) was elevated for the seagrass mead- 

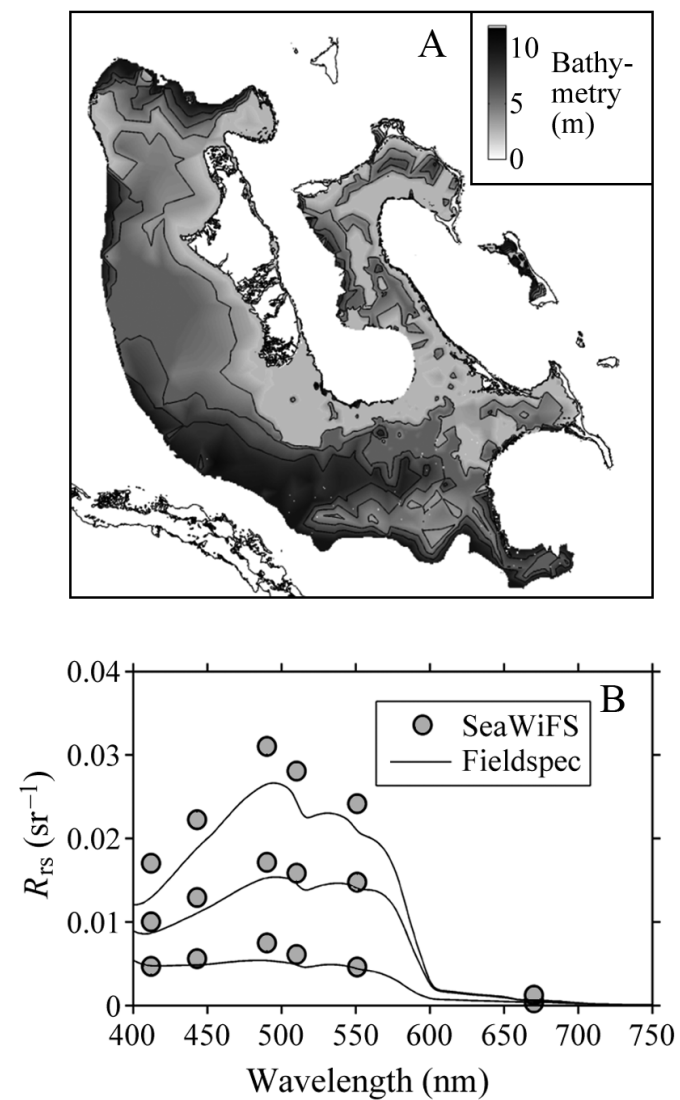
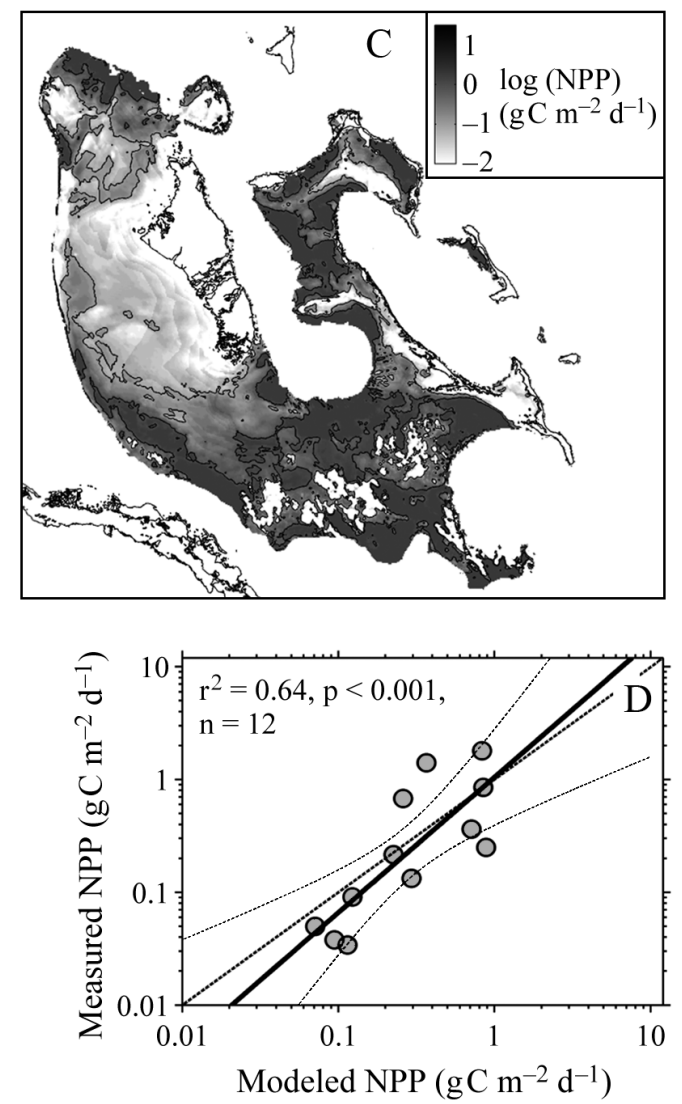

Fig. 6. (A) Digitized and gridded bathymetry across the Great Bahama Bank from 0 to $10 \mathrm{~m}$. (B) Satellite-derived remote sensing reflectance $\left(R_{\mathrm{rs}}\right)$ from SeaWiFS imagery $(O)$ in comparison to field measurements from 3 diverse stations (solid lines). sr $=$ steradians (C) Modeled net primary productivity (NPP, $\mathrm{gC} \mathrm{m}^{-2} \mathrm{yr}^{-1}$ ) derived from SeaWiFS imagery over the entire Bahamas Banks. (D) Logarithmic comparison of satellite-modeled NPP from stations throughout the banks and estimates made during the field campaign $\left(r^{2}=0.64, p<0.01\right)$. Thin dashed lines represent $95 \%$ confidence intervals and the thick dashed line is the $1: 1$ line

ows. For those regions with NPP $>0.3 \mathrm{~g} \mathrm{C} \mathrm{m}^{-2} \mathrm{~d}^{-1}$, we evaluated the retrieved $R_{\mathrm{B}}(440): R_{\mathrm{B}}(555)$ ratio derived from the imagery. A higher ratio was presumed to be predominantly seagrass and a lower ratio was either macro- or microalgae. An analysis was conducted to determine the empirical threshold of the blue:green $R_{\mathrm{B}}$ ratio which best discriminated seagrass from the algae. The threshold was allowed to vary in 0.01 increments from 0 to 2 until the highest agreement was reached between the model and the in situ identification of the benthos. Seagrass was modeled as those pixels with a blue:green $R_{\mathrm{B}}$ ratio $>0.7$ and algae below this empirical threshold (Fig. 7A). Sand was considered to be pixels with modeled NPP $<0.3 \mathrm{~g} \mathrm{C} \mathrm{m}^{-2} \mathrm{~d}^{-1}$.

A classification accuracy matrix (Fig. 7B) illustrates the model which correctly retrieved the highest number of stations. The rows in the matrix represent the dominant benthic constituent identified at the field stations and the columns represent the benthic class identified from the satellite imagery. If all of the stations were mapped correctly, then numbers will only appear in the diagonal boxes where each benthic class inter- sects; in all cases, the sum of the diagonals is used to calculate the overall accuracy. Benthic classes at 17 of the 23 field stations ( $73 \%$ ) were correctly identified by the classification technique. The off diagonals show errors where a portion of the map is omitted from the correct category (omission error) and placed in an incorrect category (commission error). For the seagrass stations, $71 \%$ were correctly identified and $29 \%$ were misidentified as bare sediment. Similarly, $83 \%$ of the sediment pixels were correctly identified and only $17 \%$ were misidentified as seagrass. No commission errors occurred for algae. For algae, $50 \%$ of the 4 stations were misidentified as either sediment $(25 \%)$ or seagrass $(25 \%)$. However, the technique correctly identified algal stations along the central Exumas, the largest algal-dominated region that was sampled. Applying this model throughout the satellite image (Fig. 7A), seagrass accounted for $4.1 \times 10^{10} \mathrm{~g} \mathrm{C} \mathrm{d}^{-1}$ and covered roughly $40000 \mathrm{~km}^{2}$, while algae accounted for $3.3 \times 10^{9} \mathrm{~g} \mathrm{C} \mathrm{d}^{-1}$ and covered only $4500 \mathrm{~km}^{2}$. A majority of the GBB $\left(50000 \mathrm{~km}^{2}\right)$ was comprised of bare sediment. 


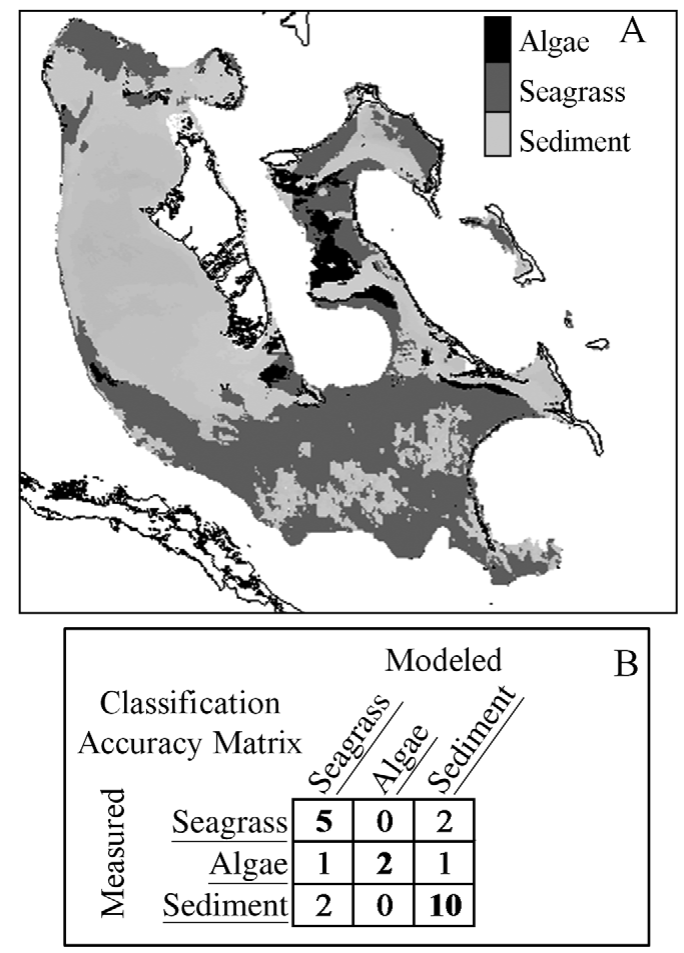

Fig. 7. (A) Mapped distributions of algae (either macro- or microalgae), seagrass, and bare sediment on the Great Bahama Bank. (B) Classification accuracy matrix: diagonal values (bold) indicate the number of stations that were accurately classified in each category. Values outside the diagonal were misclassified stations either due to errors in the algorithm or variability in the spatial scale between single station measurements and estimates derived over the $1 \mathrm{~km}^{2}$ pixel area

\section{DISCUSSION}

Field measurements from the GBB revealed several different types of benthic habitats: seagrass, brown and red macroalgae, and sediment with and without microalgal biofilm. Sediment with little microalgal biofilm or seagrass was considered the prevalent benthic habitat, covering nearly $50000 \mathrm{~km}^{2}$ of the bank. Seagrass meadows were found to be the dominant producer on the bank. Moderate to dense stands, primarily of turtle grass, were mapped over $37000 \mathrm{~km}^{2}$ of the bank and occurred primarily along the perimeters of the GBB and throughout the southern bank. Due to high winds and logistical factors, we were unable to directly sample the southern portions of the bank where much of the productive seagrass meadows were identified from space; future field campaigns to this remote central/southern section of the bank will be required to validate our map.

Using the lower bound estimate of growth, NPP estimated for the densest seagrass meadows was on the order of $0.8 \mathrm{gC} \mathrm{m}^{-2} \mathrm{~d}^{-1}$. NPP estimates based on in situ leaf-punch studies were in reasonable agreement with the laboratory measurements of leaf metabolism and varied by $<20 \%$ for different ranges of LAI. The higher rates of NPP measured in 2002-2003 near Lee Stocking Island (see Fig. 2B) were comparable to measurements by Koch \& Madden (2001) of 1.65 to $2.29 \mathrm{~g} \mathrm{C} \mathrm{m}^{-2}$ $\mathrm{d}^{-1}$ in a lagoon on Grand Bahama Island (Little Bahama Bank) using in situ benthic chambers.

Benthic algae from the GBB included brown and red macroalgae, as well as microalgae associated with sediment. Benthic diatoms have been identified as the dominant microalgae associated with all sediment types including peloidal, oolitic, and grapestone sediments (Stephens et al. 2003). Measured rates of algal NPP varied widely depending on the type and concentration of algae present on the seafloor. NPP of brown macroalgae found in thick 3 to $10 \mathrm{~cm}$ drifts in the Exumas regions (Dierssen et al. 2009b) was very high, upwards of 18 to $30 \mathrm{~g} \mathrm{C} \mathrm{m}^{-2} \mathrm{~d}^{-1}$ depending on macroalgal density. In contrast, NPP of grapestone with relatively thin biofilm was barely net autotrophic $(0.005 \mathrm{~g} \mathrm{C}$ $\mathrm{m}^{-2} \mathrm{~d}^{-1}$ ). Average NPP for tropical macrophyte-dominated ecosystems has been reported between these 2 extremes at $\sim 37 \mathrm{~mol} \mathrm{C} \mathrm{m}{ }^{-2} \mathrm{yr}^{-1}$ or roughly $1.2 \mathrm{~g} \mathrm{C} \mathrm{m}^{-2}$ $\mathrm{d}^{-1}$ (Gattuso et al. 1998).

Within the confines of this multi-spectral analysis, no distinct spectral signature was found to effectively differentiate micro- and macroalgae. Derivative analysis showed several spectral wavebands, particularly between 505 and $550 \mathrm{~nm}$, where various producers could be differentiated based on spectral slope changes that may be useful should higher spectral resolution imagery become routinely available. With additional spectral information (Phinn et al. 2008) and other coincident measurements and analysis (e.g. LIDAR, texture analysis, etc.), it may be possible to further refine the remote sensing tools to better estimate the vastly different productivity rates of micro- and macroalgae. This analysis suggests that highly productive algae cover roughly $4500 \mathrm{~km}^{2}$ of the seafloor and represent $7 \%$ of the total NPP, but this number may be on the low side when considering ephemeral blooms of algae and with inclusion of sediment algae within the seagrass meadows.

Total NPP estimated across the entire GBB was $5 \times$

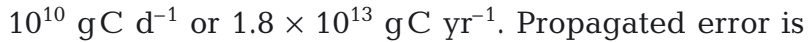
difficult to constrain given the level of complexity in the input data and model formulation. However, results from Fig. 6D suggest that the NPP estimate may be accurate to roughly within a factor of 2 . Seagrass ecosystems across the GBB represent around $0.04 \%$ of the total ocean productivity of $48 \times 10^{15} \mathrm{gC} \mathrm{yr}^{-1}$ (Longhurst et al. 1995). If these rates are consistent across the $\sim 800000 \mathrm{~km}^{2}$ of shallow water carbonate sediment banks scattered throughout the world (Milli- 
man 1993), productivity in carbonate systems equals roughly $0.3 \%$ of global annual ocean productivity. This is consistent with previous estimates of global seagrass NPP (Mateo et al. 2006). Applying these techniques over more coastal habitats could lead to better constrained estimates of seagrass to global NPP.

Errors in the NPP estimates derived from spacebased imagery arise from many sources including atmospheric correction, bathymetry, water column optical properties, and variability in estimating NPP from the different producers. The atmospherically corrected sea spectral reflectance derived over the bank was representative in magnitude and spectral shape across a variety of dark and bright stations sampled field (see Fig. 6B). For this analysis, bathymetry was digitized from charts because good agreement could not be reached between in situ measurements and optical methods. Bathymetry maps of the GBB from SeaWiFS (Stumpf et al. 2003) and Medium Resolution Imaging Spectrometer (Lee et al. 2007) imagery showed many of the same features reproduced in the present study and these techniques hold great promise for future retrievals. In addition, bathymetry and benthic properties can be simultaneously retrieved from airborne and spaceborne hyperspectral sensors (Kutser et al. 2006, Lesser \& Mobley 2007).

A look-up table based on a single set of mean water column inherent optical properties was used to model bottom reflectance across the GBB. Estimates of bottom reflectance would be $\sim 15 \%$ lower and NPP approximately 15 to $20 \%$ higher if the higher attenuation values were used across the entire bank. The higher attenuation rates west of Andros, however, were primarily associated with fine mud sediments that have little to no productivity and may not be representative of the water column overlying benthos with higher NPP. Dense seagrass meadows can reduce currents inside the beds (Scoffin 1970) and can decrease the particle load in the water (Buonassissi 2009). Moreover, the inherent optical properties used in the radiative transfer modeling were in the range of those measured around Lee Stocking Island (Boss \& Zaneveld 2003) and may be generally representative of conditions in these oligotrophic waters, although some variability in absorption by colored dissolved matter may be evident at different tidal stages (Otis et al. 2004). A further nuanced approach to the modeling would incorporate different water column optical properties expected for different benthic substrates (Boss \& Zaneveld 2003) and environmental conditions (e.g. tides and winds) (Monahan 1993).

In addition to the error inherent to the empirical regression, estimates of NPP may also be in error because they do not account for total system-wide NPP within seagrass meadows. Seagrass NPP estimated from leaf growth rates represent the lower bound for seagrass production, because they do not include the growth of below-ground roots and rhizomes or production by other autotrophs associated with seagrass meadows. For these types of seagrass meadows, below-ground productivity may be as much as $35 \%$ of above-ground production (Duarte \& Chiscano 1999).

NPP in seagrass systems is further enhanced by the larger autotrophic community consisting of phytoplankton, epiphytic algae, and benthic macro- and microalgae. In these clear waters, mean phytoplankton biomass estimated from the 2004 field season was $0.12 \mathrm{mg}$ chl a $\mathrm{m}^{-3}$, which roughly translates to primary production of $9 \mathrm{~g} \mathrm{C} \mathrm{m}^{-2} \mathrm{yr}^{-1}$ (Behrenfeld \& Falkowski 1997), an insignificant contribution. Seagrass systemwide productivity may also be altered by epiphytic growth on the seagrass leaves and microalgae within the sediment. Epiphytes do not act merely as neutraldensity filters situated above the seagrass leaves, but compete for photons with the underlying leaves (Drake et al. 2003, Fyfe 2003). Turtle grass epiphytes from near Lee Stocking Island, Bahamas, absorbed a maximum of $36 \%$ of incident light in peak chlorophyll absorption bands and negatively impacted spectral photosynthesis of their seagrass hosts. For the oxygen evolution measurements in this analysis, however, epiphytes were left intact and NPP estimates should be inclusive of both leaf and epiphyte productivity rates. Benthic microalgae from the upper layer of sediment are highly variable across the Bahamas, as noted previously, and some productivity is expected to occur within sediment from the seagrass meadows themselves. Consequently, system-wide production within seagrass may be over 2-fold greater than the aboveground seagrass production reported here.

Finally, seagrass photosynthesis in seawater is inherently $\mathrm{CO}_{2}$-limited and seagrass productivity may increase in response to rising $\mathrm{CO}_{2}$ levels in the atmosphere, increasing both the flux of organic carbon to the sediments and the rates of carbonate dissolution (Zimmerman et al. 1997, Invers et al. 2001, Palacios \& Zimmerman 2007). Rising atmospheric $\mathrm{CO}_{2}$ may initiate a positive feedback, further enhancing the sequestration of $\mathrm{CO}_{2}$ into bicarbonate by promoting dissolution of carbonate sediments on shallow banks that are heavily vegetated by seagrasses (Burdige et al. 2008). If the vast majority of seagrass biomass decomposes in the sediments, seagrass productivity across the GBB alone may sequester as much as $2.4 \times 10^{13} \mathrm{gC} \mathrm{yr}^{-1}$ (sum of above- and below-ground productivity), representing nearly $1 \%$ of the annual oceanic $\mathrm{CO}_{2}$ uptake of $2.2 \times 10^{15} \mathrm{~g} \mathrm{C} \mathrm{yr}^{-1}$ (Feely et al. 2001). If these rates are consistent across all carbonate sediment banks ( 800 $000 \mathrm{~km}^{2}$; Milliman 1993), seagrass productivity may be responsible for as much as $8 \%$ of the ocean's 
annual net $\mathrm{CO}_{2}$ uptake. Transient macroalgal blooms, on the other hand, may be associated with wind-driven processes along the Exumas (Dierssen et al. 2009b), and their abundance has been associated with nutrient enrichment in coastal estuaries (Valiela et al. 1997). Benthic microalgal communities serve to provide food to higher trophic levels and modify nutrient exchange between the water column and sediments (MacIntyre et al. 1996, Berelson et al. 1998). Being able to monitor the present and future distributions and productivity of these various benthic producers will be important as these regions are influenced by both natural and anthropogenic changes. Enhanced spatial and particularly spectral resolution imagery from satellites may afford better capabilities for such future monitoring and analysis.

Acknowledgements. Thanks are extended to S. Bailey and M. Reubens from SeaDAS for help in atmospheric correction of the imagery, L. Bodensteiner for the underwater photography, E. Powell for assistance digitizing bathymetry, the crew and researchers aboard the RV 'Walton Smith', and the Exuma Land and Sea Park. This work was supported by National Aeronautics and Space Administration's Ocean Biology and Biogeochemistry research program (NNG04GN61G to H.M.D. and R.C.Z.), New Energy Development Organization of Japan, National Science Foundation (Chemical Oceanography Program to D.J.B. and R.C.Z.), Caribbean Marine Research Center, and National Undersea Research Program. Productivity measurements from Lee Stocking Island were supported by the Office of Naval Research (N0014-97-10032 to R.C.Z.).

\section{LITERATURE CITED}

Armstrong RA (1993) Remote sensing of submerged vegetation canopies for biomass estimation. Int J Remote Sens 14:621-627

Behrenfeld MJ, Falkowski PG (1997) Photosynthetic rates derived from satellite-based chlorophyll concentration. Limnol Oceanogr 42:1-20

Berelson WM, Heggie D, Longmore A, Kilgore T, Nicholson G, Skyring G (1998) Benthic nutrient recycling in Port Phillip Bay, Australia. Estuar Coast Shelf Sci 46:917-934

Boss E, Zaneveld JRV (2003) The effect of bottom substrate on inherent optical properties: evidence of biogeochemical processes. Limnol Oceanogr 48:346-354

Brush MJ, Nixon SW (2003) Biomass layering and metabolism in mats of the macroalga Ulva lactuca L. Estuaries 26: 916-926

Buonassissi C (2009) A regional comparison of particle size distributions and the power-law approximation in oceanic and estuarine surface waters by laser diffraction. MS thesis, University of Connecticut, Storrs, CT

Burdige DG, Zimmerman RC (2002) Impact of sea grass density on carbonate dissolution in Bahamian sediments. Limnol Oceanogr 47:1751-1763

Burdige D, Zimmerman R, Hu X (2008) Rates of carbonate dissolution in permeable sediments estimated from porewater profiles: the role of sea grasses. Limnol Oceanogr 53:549-565

Dekker AG, Brando VE, Anstee JM (2005) Retrospective sea- grass change detection in a shallow coastal tidal Australian lake. Remote Sens Environ 97:415-433

Dekker A, Brando V, Anstee J, Fyfe S, Malthus T, Karpouzli E (2006) Remote sensing of seagrass ecosystems: use of spaceborne and airborne sensors. In: Larkum AWD, Orth RJ, Duarte CM (eds) Seagrasses: biology, ecology, and conservation. Springer, Dordrecht, p 347-359

Dierssen HM, Zimmerman RC, Leather RA, Downes TV, Davis CO (2003) Ocean color remote sensing of seagrass and bathymetry in the Bahamas Banks by high resolution airborne imagery. Limnol Oceanogr 48:456-463

> Dierssen HM, Zimmerman RC, Burdige D (2009a) Optics and remote sensing of Bahamian carbonate sediment whitings and potential relationship to wind-driven Langmuir Circulation. Biogeosciences 6:487-500

Dierssen, HM, Zimmerman RC, Burdige D, Drake L (2009b) Potential export of unattached benthic macroalgae to the deep sea through wind-driven Langmuir circulation. Geophys Res Lett 36:L04602 doi:101029/2008GL036188

Drake LA, Dobbs FC, Zimmerman RC (2003) Effects of epiphyte load on optical properties and photosynthetic potential of the seagrasses Thalassia testudinum Banks ex Konig and Zostera marina L. Limnol Oceanogr 48:456-463

Duarte CM, Cebrian J (1996) The fate of marine autotrophic production. Limnol Oceanogr 41:1758-1766

Duarte CM, Chiscano CL (1999) Seagrass biomass and production: a reassessment. Aquat Bot 65:159-174

Feely RA, Sabine CL, Takahashi R, Wanninkhof R (2001) Uptake and storage of carbon dioxide in the ocean: the global $\mathrm{CO}_{2}$ survey. Oceanography 14:18-32

Fyfe SK (2003) Spatial and temporal variation in spectral reflectance: Are seagrass species spectrally distinct? Limnol Oceanogr 48:464-479

Gattuso JP, Frankignoulle M, Wollast R (1998) Carbon and carbonate metabolism in coastal aquatic ecosystems. Annu Rev Ecol Syst 29:405-434

- Gordon HR (1997) Atmospheric correction of ocean color imagery in the Earth Observing System era. J Geophys Res 102:17,081-17,106

Gould RW, Arnone RA, Sydor M (2001) Absorption, scattering, and remote-sensing reflectance relationships in coastal waters: testing a new inversion algorithm. J Coast Res 17:329-341

Hu X (2007) Seagrass-mediated carbonate dissolution and early diagenesis in Bahamas Bank sediments. $\mathrm{PhD}$ dissertation, Old Dominion University, Norfolk, Virginia

Invers O, Zimmerman R, Alberte R, Perez M, Romero J (2001) Inorganic carbon sources for seagrass photosynthesis: an experimental evaluation for bicarbonate use in temperate species. J Exp Mar Biol Ecol 265:203-217

Kelly MG (1980) Remote sensing of seagrass beds. In: Phillips RC, McRoy CP (eds) Handbook of seagrass biology: an ecosystem perspective. Garland STPM Press, New York, p 69-85

> Koch MS, Madden CJ (2001) Patterns of primary production and nutrient availability in a Bahamas lagoon with fringing mangroves. Mar Ecol Prog Ser 219:109-119

Kutser T, Miller I, Jupp DLB (2006) Mapping coral reef benthic substrates using hyperspectral space-borne images and spectral libraries. Estuar Coast Shelf Sci 70:449-460

> Lee ZP, Carder KL, Mobley CD, Steward RG, Patch JS (1999) Hyperspectral remote sensing for shallow waters: 2 . Deriving bottom depths and water properties by optimization. Appl Optics 38:3831-3843

Lee ZP, Hu C, Gray D, Casey B and others (2007) Properties of coastal waters around the US: preliminary results using MERIS data. Proc Envisiat Symp, Montreux, Switzerland, 


\section{3-27 April 2007}

Lesser MP, Mobley CD (2007) Bathymetry, water optical properties, and benthic classification of coral reefs using hyperspectral remote sensing imagery. Coral Reefs 26:819-829

Longhurst A, Sathyendranath S, Platt T, Caverhill C (1995) An estimate of global primary productivity in the ocean from satellite radiometer data. J Plankton Res 17:1245-1271

Louchard EM, Reid RP, Stephens FC, Davis CO, Leathers RA, Downes TV (2003) Optical remote sensing of benthic habitats and bathymetry in coastal environments at Lee Stocking Island, Bahamas: a comparative spectral classification approach. Limnol Oceanogr 48:511-521

MacIntyre HL, Geider RJ, Miller DC (1996) Microphytobenthos: the ecological role of the 'secret garden' of unvegetated, shallow-water marine habitats. I. Distribution, abundance and primary production. Estuaries 19:186-201

Maptech (2004) Region 9.2 Central Bahamas. Maptech, Amesbury, MA

Maritorena S, Morel A, Gentili B (1994) Diffuse reflectance of oceanic shallow waters: influence of water depth and bottom albedo. Limnol Oceanogr 39:1689-1703

Mateo MA, Cebrian J, Dunton K, Mutchler T (2006) Carbon flux in seagrasses. In: Larkum AWD, Orth RJ, Duarte CM (eds) Seagrasses: biology, ecology, and conservation. Springer, Dordrecht, p 159-192

Milliman JD (1993) Production and accumulation of calcium carbonate in the ocean: budget of a nonsteady state. Global Biogeochem Cycles 7:927-957

Mobley CD (1994) Light and water: radiative transfer in natural waters. Academic Press, San Diego

Mobley CD (1999) Estimation of the remote-sensing reflectance from above-surface measurements. Appl Optics 38: $7442-7455$

Mobley CD, Sundman JK, Davis CO, Bowles JH and others (2005) Interpretation of hyperspectral remote-sensing imagery by spectrum matching and look-up tables. Appl Opt 44:3576-3592

Monahan E (1993) Occurrence and evolution of acoustically relevant sub-surface bubble plumes and their associated, remotely monitorable surface whitecaps. In: Kerman BR (ed) Natural physical sources of underwater sound: sea surface sound. Kluwer Academic Publishers, Dordrecht, p 503-518

Otis DB, Carder KL, English DC, Ivey JE (2004) CDOM transport from the Bahamas Banks. Coral Reefs 23:152-160

Palacios SL, Zimmerman RC (2007) Response of eelgrass Zostera marina to $\mathrm{CO}_{2}$ enrichment: possible impacts of climate change and potential for remediation of coastal habitats. Mar Ecol Prog Ser 344:1-13

Petersen CGJ (1918) The sea bottom and its production of fish-food. Rep Dan Biol Stn 25:1-62

Phinn S, Roelfsema C, Dekker A, Brando V, Anstee J (2008) Mapping seagrass species, cover and biomass in shallow waters: an assessment of satellite multi-spectral and airborne hyper-spectral imaging systems in Moreton Bay (Australia). Remote Sens Environ 112:3413-3425

Robbins LL, Tau Y, Evans CA (1997) Temporal and spatial distribution of whitings on the Great Bahama Bank and a

Editorial responsibility: Rodney Forster,

Lowestoft, UK new lime mud budget. Geology 25:947-950

Scoffin TP (1970) The trapping and binding of subtidal carbonate sediments by marine vegetation in Bimini Lagoon, Bahamas. J Sediment Petrol 40:249-273

Shinn EA, Steinen RP, Lidz BH, Swart PK (1989) Whitings, a sedimentologic dilemma. J Sediment Petrol 59:147-161

Short FT (1980) A simulation model of the seagrass production system. In: Phillips RC, McRoy CP (eds) Handbook of seagrass biology: an ecosystem perspective. Garland STPM Press, New York, p 277-296

Short FT, Wyllie-Echeverria S (1996) Natural and humaninduced disturbance of seagrasses. Environ Conserv 23: $17-27$

Smith SV (1981) Marine macrophytes as a global carbon sink. Science 211:838-840

Stephens FC, Louchard EM, Reid RP, Maffione RA (2003) Effects of microalgal communities on reflectance spectra of carbonate sediments in subtidal optically shallow marine environments. Limnol Oceanogr 48:535-546

Stramski D, Boss E, Bogucki D, Voss KJ (2004) The role of seawater constituents in light backscattering in the ocean. Prog Oceanogr 61:27-56

Stumpf RP, Holderied K, Robinson JA, Feldman G, Kuring N (2003) Mapping water depths in clear water from space. Proc 13th Biennial Coastal Zone Conf, NOAA Coastal Services Center, Baltimore, MD, July 13-17, 2003, NOAA Coastal Services Center, NOAA/CSC/20322-CD, Charleston, SC

Twardowski MS, Boss E, Macdonald JB, Pegau WS, Barnard AH, Zaneveld JRV (2001) A model for estimating bulk refractive index from the optical backscattering ratio and the implications for understanding particle composition in case I and case II waters. J Geophys Res 106:14129-14142

Valiela I, McClelland J, Hauxwell J, Behr PJ, Hersh D, Foreman K (1997) Macroalgal blooms in shallow estuaries: controls and ecophysiological and ecosystem consequences. Limnol Oceanogr 42:1105-1118

Vergara J, Perez-Llorens LP, Peralta G, Hernandez I (1997) Seasonal variation of photosynthetic performance and light attenuation in Ulva canopies from Palmones River Estuary. J Phycol 33:773-779

Winland HD, Matthews RK (1974) Origin and significance of grapestone, Bahama Islands. J Sediment Petrol 44: 921-927

Zieman JC, Wetzel RG (1980) Productivity in seagrasses: methods and rates. In: Phillips RC, McRoy CP (eds) Handbook of seagrass biology: an ecosystem perspective. Garland STPM Press, New York, p 87-116

Zieman JC, Thayer GW, Robblee MB, Zieman RT (1979) Production and export of seagrasses from a tropical bay. In: Livingston RJ (eds) Ecological processes in coastal and marine systems. Plenum Press, New York, p 21-33

Zimmerman R (2003) A biooptical model of irradiance distribution and photosynthesis in seagrass canopies. Limnol Oceanogr 48:568-585

Zimmerman RC, Kohrs DG, Steller DL, Alberte RS (1997) Impacts of $\mathrm{CO}_{2}$ enrichment on productivity and light requirements of eelgrass. Plant Physiol 115:599-607

Submitted: July 28, 2009; Accepted: May 12, 2010

Proofs received from author(s): June 21, 2010 